Supporting information for

\title{
Riboflavin-mediated photooxidation of gold nanoparticles and its effect on the inactivation of bacteria.
}

María Belén Rivas Aiello ${ }^{a^{*}}$, Fiorela Ghilini ${ }^{a}$, Joaquín E. Martínez Porcel ${ }^{a}$, Lisandro Giovanetti ${ }^{\mathrm{a}}$, Patricia L. Schilardi ${ }^{\mathrm{a}}$ and Daniel O. Mártire ${ }^{\mathrm{a}^{*}}$.

anstituto de Investigaciones Fisicoquímicas Teóricas y Aplicadas (INIFTA), Facultad de Ciencias Exactas, Universidad Nacional de La Plata, CONICET, La Plata, Argentina.

Corresponding Authors: E-mail: MBRA: belenra@inifta.unlp.edu.ar, DOM: dmartire@inifta.unlp.edu.ar.

Number of pages: 5

Number of figures: 5

Number of schemes: 0

Number of tables: 1

\section{Contents:}

Figure S1: TEM images and size distribution histogram of

PecAuNP. $\mathrm{S2}$

Figure S2: Absorption spectra of Rf with and without PecAuNP....................... S2

Table S1: Fluorescence lifetime measurements.............................................. S3

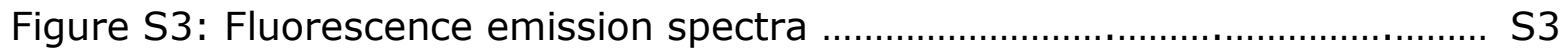

Figure S4: EADS obtained for the different components in the absence and presence of different concentrations of PecAuNP. S4

Figure S5: a) Singlet oxygen phosphorescence measurements, b) Plot of [H2O2] vs

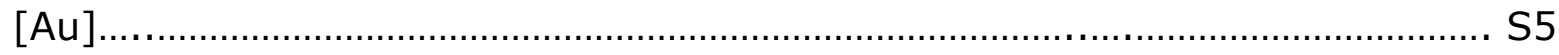



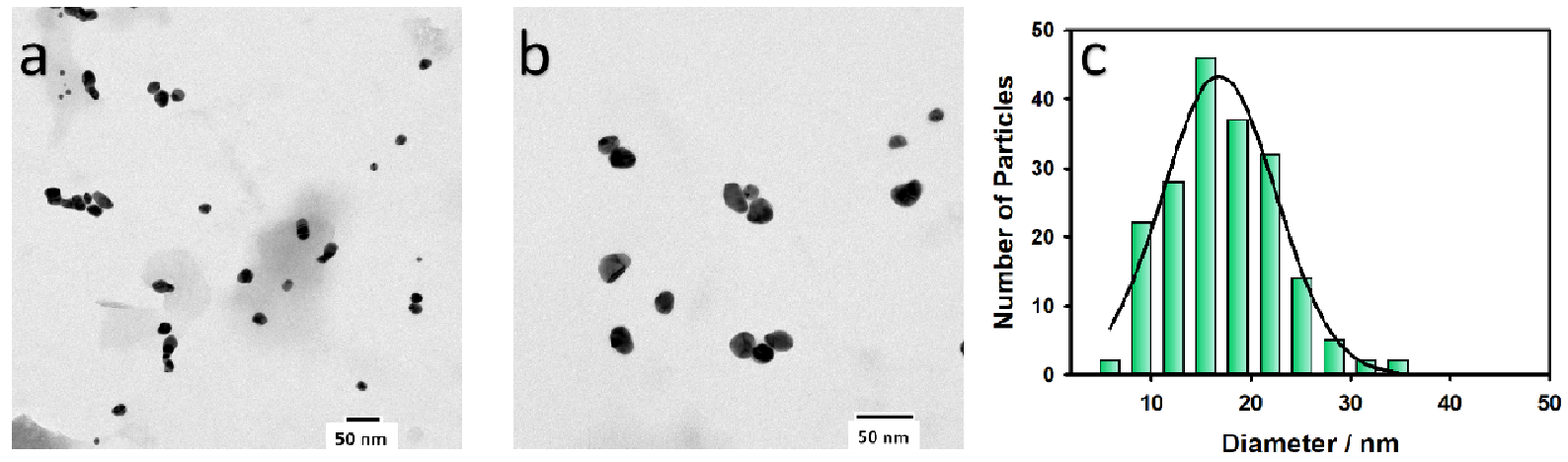

Figure S1: TEM images of PecAuNP (a and b) and size distribution histogram (c) of PecAuNP. 202 nanoparticles were counted.

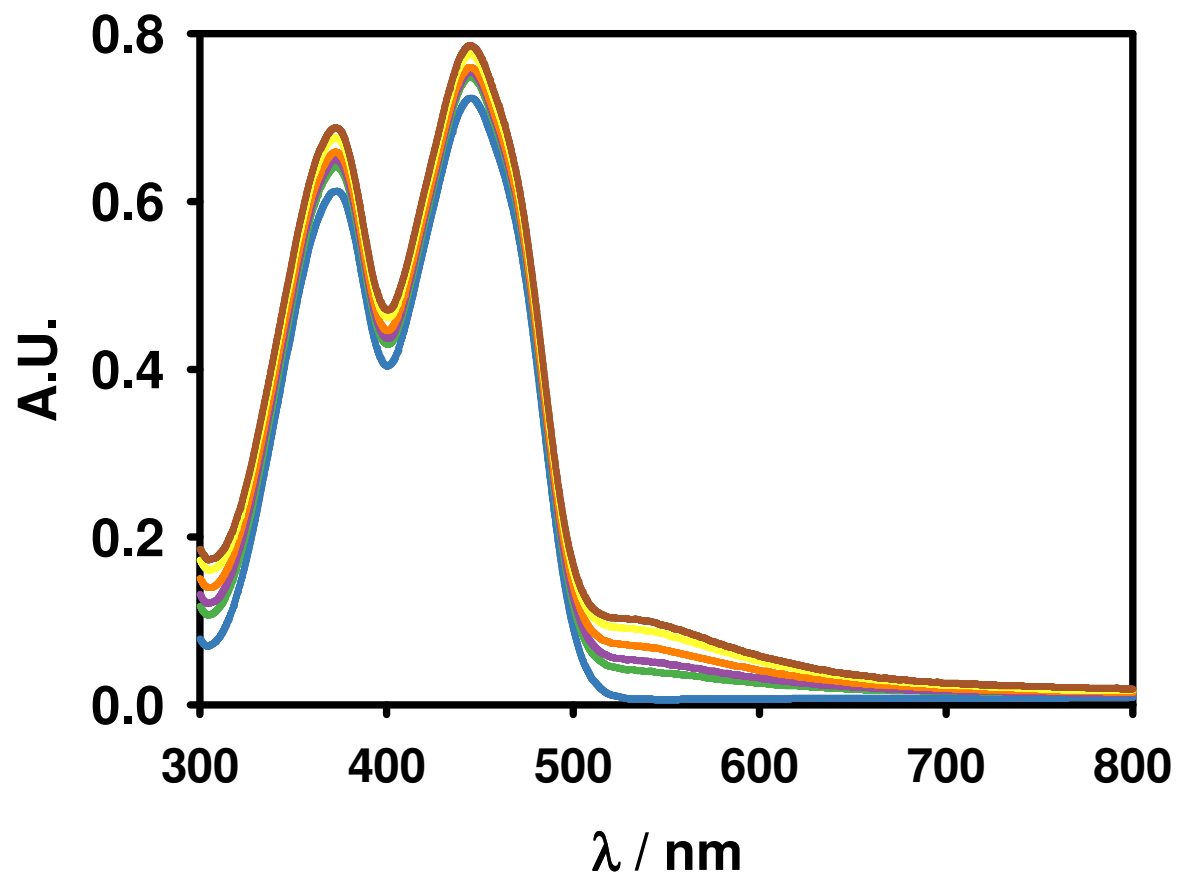

Figure S2: Absorption spectra of $\mathrm{Rf}(16 \mu \mathrm{M})$ in the absence (blue) and presence of different amounts of PecAuNP. The Au concentrations are: $1 \mu \mathrm{M}$ Au (green line), $5 \mu \mathrm{M}$ Au (purple line), $7.5 \mu \mathrm{M}$ Au (orange line), $10 \mu \mathrm{M}$ Au (yellow line) and $50 \mu \mathrm{M}$ Au (brown line). 
Table S1: Fluorescence lifetimes of Rf at different concentrations of PecAuNP.

\begin{tabular}{|c|c|}
\hline Au] / M & T / S \\
\hline 0 & $4.72 \times 10^{-9}$ \\
\hline $4.55 \times 10^{-8}$ & $4.71 \times 10^{-9}$ \\
\hline $6.83 \times 10^{-8}$ & $4.71 \times 10^{-9}$ \\
\hline $7.88 \times 10^{-8}$ & $4.72 \times 10^{-9}$ \\
\hline $9.11 \times 10^{-8}$ & $4.72 \times 10^{-9}$ \\
\hline $1.18 \times 10^{-7}$ & $4.71 \times 10^{-9}$ \\
\hline $1.58 \times 10^{-7}$ & $4.71 \times 10^{-9}$ \\
\hline $4.55 \times 10^{-7}$ & $4.73 \times 10^{-9}$ \\
\hline
\end{tabular}

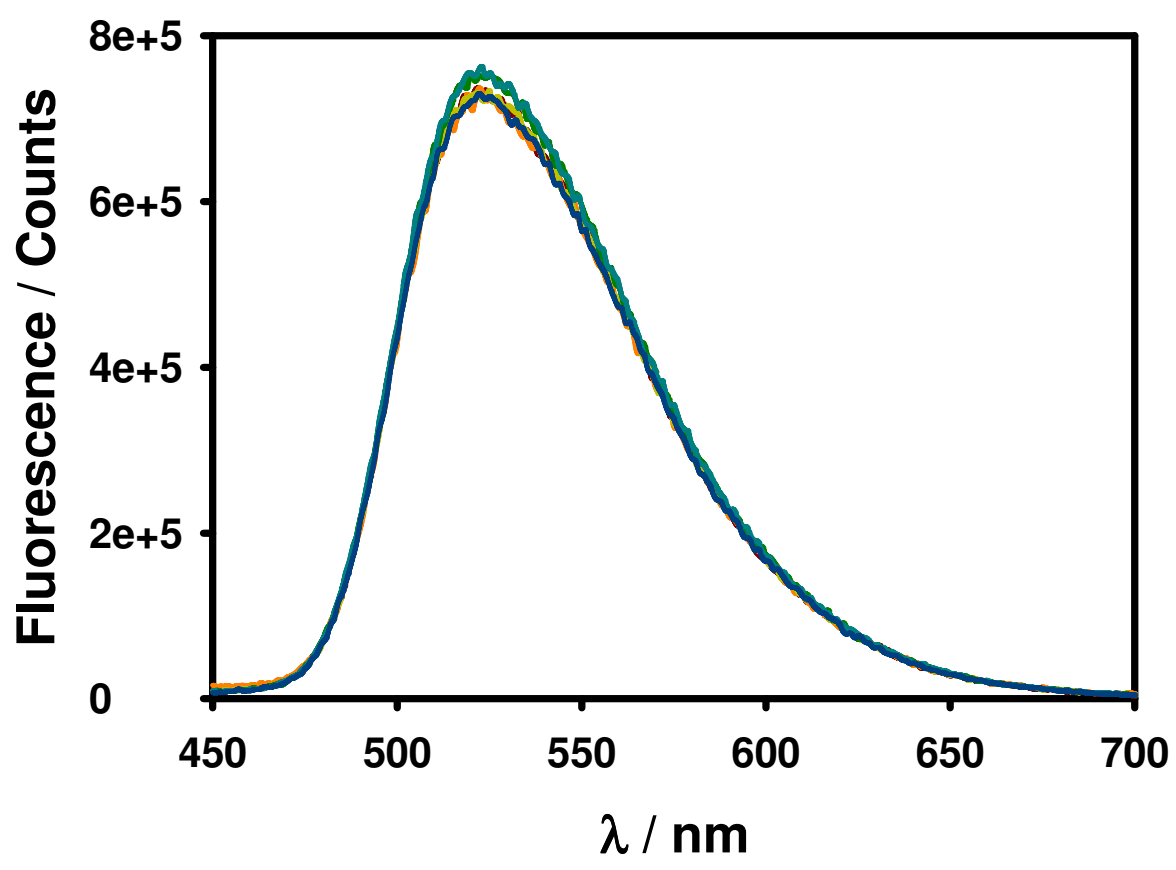

Figure S3: Corrected fluorescence emission spectra of $\operatorname{Rf}(16 \mu \mathrm{M})$ in the absence (brown) and presence of different amounts of PecAuNP. The Au concentrations are: $5 \mu \mathrm{M}$ (orange), $1 \mu \mathrm{M}$ (light green), $0.75 \mu \mathrm{M}$ (dark green), $0.50 \mu \mathrm{M}$ (blue) y $0.10 \mu \mathrm{M}$ (purple). 

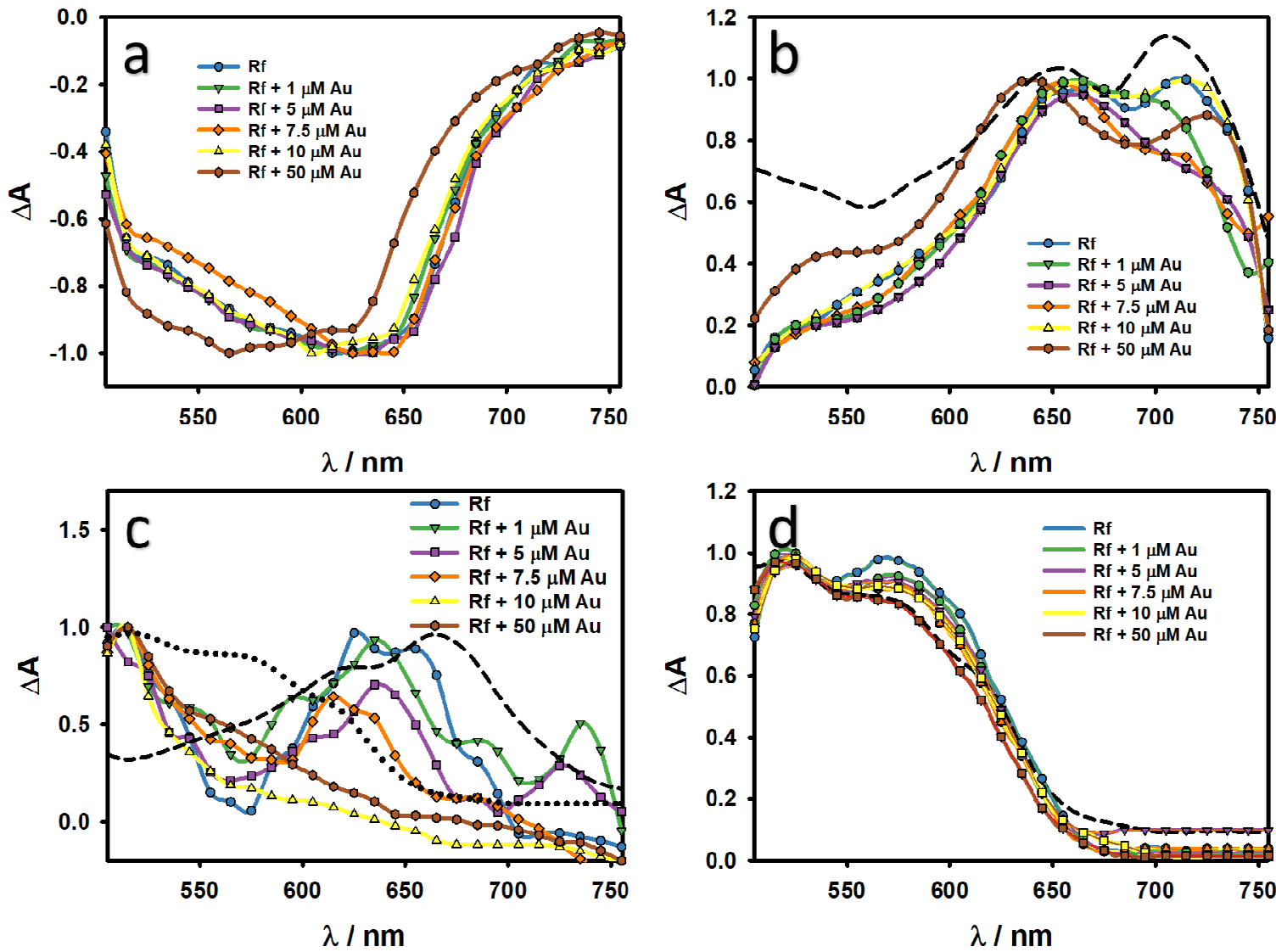

Figure S5: a) EADS obtained for the first component after $\operatorname{Rf}(53 \mu \mathrm{M})$ excitation in the absence (blue line) and presence of $1 \mu \mathrm{M}$ Au (green line), $5 \mu \mathrm{M}$ Au (purple line), $7.5 \mu \mathrm{M}$ Au (orange line), $10 \mu \mathrm{M}$ Au (yellow line) and $50 \mu \mathrm{M}$ Au (brown line). b) EADS obtained for the second component after $\operatorname{Rf}(53 \mu \mathrm{M})$ excitation in the absence (blue line) and presence of $1 \mu \mathrm{M}$ Au (green line), $5 \mu \mathrm{M}$ Au (purple line), $7.5 \mu \mathrm{M}$ Au (orange line), $10 \mu \mathrm{M}$ Au (yellow line) and $50 \mu \mathrm{M}$ Au (brown line). The triplet-triplet absorption spectrum of Rf is also shown (black dashed line) [1]. c) EADS obtained for the third component after Rf (53 $\mu \mathrm{M}$ ) excitation in the absence (blue line) and presence of $1 \mu \mathrm{M}$ Au (green line), $5 \mu \mathrm{M}$ Au (purple line), 7.5 $\mu \mathrm{M}$ Au (orange line), $10 \mu \mathrm{M}$ Au (yellow line) and $50 \mu \mathrm{M}$ Au (brown line). The radical cation of Rf (black dashed line) and neutral radical (black dotted line) absorption spectra of Rf are also shown [1]. d) EADS obtained for the fourth component after $\operatorname{Rf}(53 \mu \mathrm{M})$ excitation in the absence (blue line) and presence of $1 \mu \mathrm{M}$ Au (green line), $5 \mu \mathrm{M}$ Au (purple line), $7.5 \mu \mathrm{M}$ Au (orange line), $10 \mu \mathrm{M}$ Au (yellow line) and $50 \mu \mathrm{M}$ Au (brown line). The neutral radical absorption spectrum (black dash line) of $R f$ is also shown [1]. 

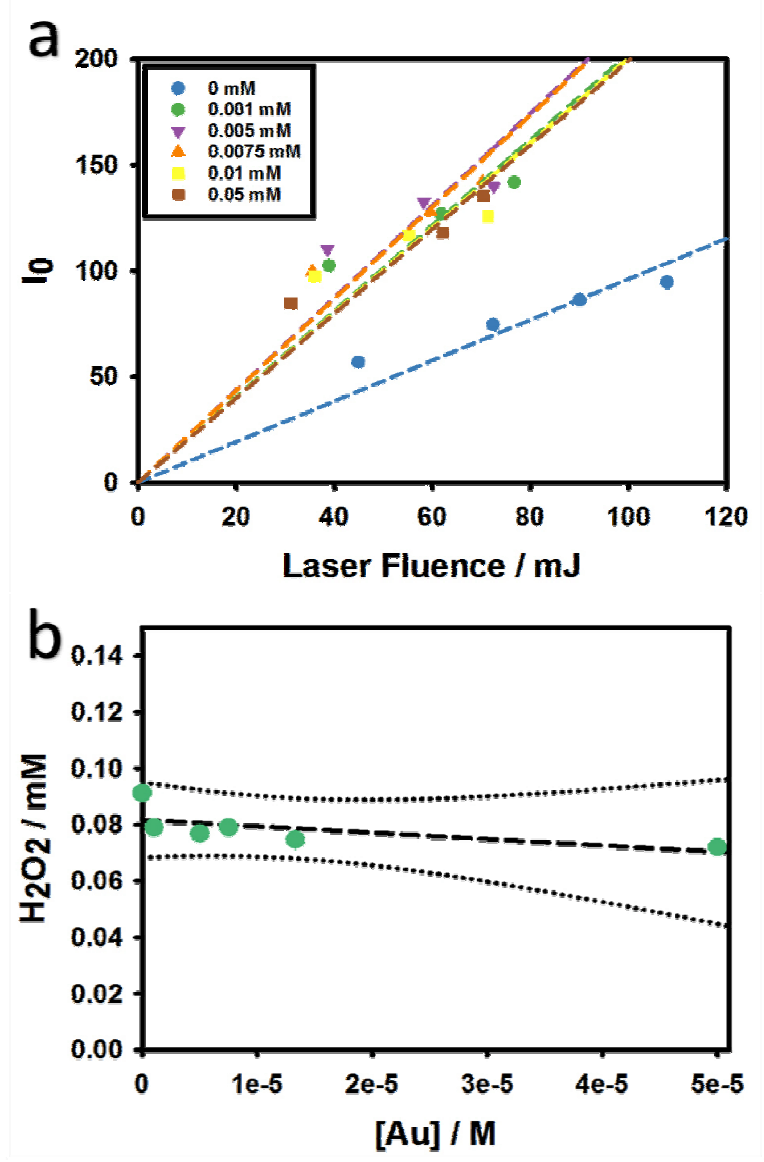

Figure S5: a) Laser fluence dependence of the time-resolved singlet oxygen phosphorescence signal extrapolated at time $=0\left(I_{0}\right)$ for $\mathrm{Rf}$ in the presence of different amounts of PecAuNP, b) Plot of $\left[\mathrm{H}_{2} \mathrm{O}_{2}\right]$ vs [Au]. The concentration of $\mathrm{Rf}$ was $0.54 \mu \mathrm{M}$.

References

1.- Li, H.; Melø, T. B.; Razi Naqvi, K. Triplets, Radical Cations and Neutral Semiquinone Radicals of Lumiflavin and Riboflavin: An Overhaul of Previous Pump-Probe Data and New Multichannel Absolute Absorption Spectra. J. Photochem. Photobiol. B Biol. 2012, 106 (1), 34-39. 